\title{
Mise en scène de la culture et espace public au Sénégal
}

\author{
Ndiouga Benga*
}

\section{Résumé}

Cette présentation suit à la trace, d'une part, la trajectoire heurtée des arts et de la culture au Sénégal sous le magistère de Senghor, président-poétephilosophe, puis de ses successeurs, dans la séquence post-indépendance et d'autre part la transformation générationnelle qui la traverse. Dans la philosophie de Senghor, où « tout est culture », le « tout État » assigne à la politique culturelle la vocation d'exprimer et de forger une identité nationale, exploitant la veine mythico-historique, s'incarnant dans des institutions culturelles voulues, créées et entretenues par les pouvoirs publics. Sous Abdou Diouf et Abdoulaye Wade, la générosité culturelle fait face à la réalité économique, caractérisée par la raréfaction des ressources. La scène culturelle se caractérise, à partir des années 1980, par l'informel, l'esprit de débrouille, l'abolition de la représentation et de la distance si chères à Senghor, la démultiplication et la déterritorialisation des initiatives culturelles. La contestation de l'État et de sa censure dans l'espace public, des années 1970 à la fin des années 1990, se donne à lire dans une tentative de culture populaire alternative, depuis le Front Culturel, en passant par le cinéma (Sembène) etles artistes indépendants du Village des Arts et de Agit-Art.

\begin{abstract}
This article traces the uneven progress of the arts and culture in Senegal under the rule of Senghor, the President-poet-philosopher, then his successors Abdou Diouf and Abdoulaye Wade, over the period running from independence to the troubled times of Structural Adjustment, little suited to cultural action. According to Senghor's philosophy, 'everything is culture' and 'all states assign to cultural policy the vocation of expressing and forging a national identity, exploiting the mythical-historical vein, embodied in cultural institutions
\end{abstract}

\footnotetext{
* Département d'Histoire, Université Cheikh Anta Diop de Dakar, Sénégal. Email : nabenga@refer.sn
} 
that are intended, created and maintained by the public authorities' [our translation]. Under Abdou Diouf and Abdoulaye Wade, cultural generosity was faced with an economic reality characterized by the depletion of resources. As of the 1980s, the cultural scène was typified by informality, a spirit of making do, the abolition of the representation and distance so dear to Senghor, and the multiplication and de-territorialization of cultural initiatives. Protests against the State and its censorship of public space, from the 1970s to the late 1990s, can be analyzed in the context of an attempt to develop an alternative popular culture, from the Front Culturel, to film (Sembène)and the independent artists of the Village des Arts and Agit-Art.

\section{Introduction}

La politique de la culture du Sénégal est marquée par la présence et l’ombre de Léopold Sédar Senghor qui mettait la culture au début et à la fin de tout le processus de développement. Cet esprit culturaliste a pesé sur la philosophie culturelle de ses successeurs Abdou Diouf (1981-2000) et Abdoulaye Wade (2000- ) au point de faire ombrage (Harney 2004:xxvi ; Hall 2009:377) à l'un dans sa définition d'une Charte culturelle et son soutien au Festival panafricain des Arts et Cultures et à l'autre de ne se définir que par rapport au père de la nation. Cette réflexion suit à la trace d'une part, la trajectoire heurtée des arts et de la culture au Sénégal sous le magistère de Senghor, président-poète-philosophe puis de ses successeurs, dans la séquence postindépendance et d'autre part, la transformation générationnelle qui la traverse. Dans la philosophie de Senghor où « tout est culture », le « tout-État » assigne à la politique culturelle la vocation d'exprimer et de forger une identité nationale, exploitant la veine mythico-historique, s'incarnant dans des institutions culturelles voulues, créées et entretenues par les pouvoirs publics. Sous Diouf et Wade, la générosité culturelle fait face à la réalité économique, caractérisée par la raréfaction des ressources. La scène culturelle se caractérise, à partir des années 1980, par l'informel, l'esprit de débrouille, l'abolition de la représentation et de la distance si chères à Senghor, la démultiplication et la déterritorialisation des initiatives culturelles. La culture s'installe dans la rue et les bidonvilles. La contestation de l'État et de sa censure dans l'espace public, des années 1970 à la fin des années 1990, se donne à lire dans une tentative de culture populaire alternative, incarnée par le Front culturel, les artistes indépendants d'Agit-Art et le cinéma de Ousmane Sembène. Au lendemain de l'alternance politique intervenue le 19 mars 2000, la scène culturelle connaît un reflux.

Il importe de faire une distinction entre les politiques publiques de la culture et les politiques culturelles. Les premières désignent l'ensemble des mesures prises par les instances publiques touchant aux activités culturelles et artistiques et les secondes s'accompagnent d'un projet social, au sens où 
l'Etat, à travers les arts et en s'appuyant sur eux essaie de changer la société. Il s'agit donc d'un projet idéologique, c'est-à-dire d'un ensemble d'idées, de concepts qui orientent le volontarisme d'Etat associé à ce projet.

D’abord, nous discuterons la politique de la culture du Sénégal, politique ici définie comme action de l'État sur la culture et la place de la culture (ici, ensemble de pratiques, de croyances, de valeurs qui renforcent l'identité d'un groupe) manipulée comme objet public, dans la politique de développement intégral de la nation sénégalaise (Diagne 2002:243 ; White 2006:13). Ensuite, nous analyserons les réactions suscitées par cette politique culturelle étatique, à travers des générations de pratiques artistiques (peinture, sculpture, cinéma).

\section{La politique de la culture comme objet public au Sénégal}

Senghor s'est attaché, au cours de sa gestion de l'État, à utiliser l'espace public non pas comme un lieu discursif de la délibération, mais pour façonner l'opinion à sa politique de la Négritude et du socialisme africain. Il donne un sens à l'action culturelle publique en mettant cette idée au sommet de l'Etat et en prêtant un enjeu social important aux arts pour conforter le tissu social.

Elle est à la fois retour à soi et ouverture à l'autre. C'est dans ce sens que Senghor parle d' « enracinement et ouverture » (Senghor 1964:22-38 ; Mbengue 1973:14). À l'origine, la négritude durant la période des années 1930 est un projet politique modéré pour réformer la colonisation française. Les écrivains porteurs de ce mouvement intellectuel n'avaient pas explicitement appelé pour l'indépendance politique des peuples colonisés. Ils avaient délibérément collaboré avec l'humanisme colonial, quelquefois s'opposaient à lui et inconsciemment reproduisaient plusieurs de ses positions. En identifiant les limites de la négritude, on peut avancer que Senghor, Césaire et Damas étaient confrontés à des impasses structurelles relevant à la fois de leur appartenance à l'héritage de l'histoire impériale française et à sa nécessaire critique (Wilder 2005:150 ; Vaillant 2006:164-166).

Au lendemain des indépendances, la responsabilité des élites était la promotion du développement économique afin d'assurer le mieux-être des populations, en luttant contre les misères du sous-développement (faim, analphabétisme, maladie...). Cette bataille n'était pas seulement celle de l'Afrique, mais celle de la Civilisation toute entière, pour parler comme Senghor. Il proposait un effort de pensée prospective. Une nation ne se réalisait pas uniquement par le développement économique, au sens où elle n'est pas seulement un ensemble d'intérêts ; la Nation était d'abord l'expression d'une civilisation originale, informée, selon son propre mouvement. Elle devait résoudre ses problèmes d'une manière novatrice, 
par un attachement à ses valeurs qui conditionnait son progrès. Il s'agissait de transmettre aux jeunes générations, par l'introduction des techniques modernes, les valeurs de la Négritude. La priorité du Développement ne devait pas faire oublier la primauté de la Culture, comme contribution à la Civilisation de l'Universel (Senghor 1977:185) qui est un humanisme intégral, horizon et finalité. Par ailleurs, cette importance de la culture dans la politique du développement s'adossait au constat que les grands courants artistiques mondiaux s'intéressaient tous aux arts africains et négro-africains, dans les domaines de la peinture, de la sculpture, de la musique et de la danse. Or la libération de l'Afrique, placée dans un contexte de développement économique et social, risquait de faire passer au second plan les problèmes de conservation, de formulation, d'évolution technique des arts traditionnels. Reprochant à la colonisation d'avoir porté un coup au patrimoine culturel africain, en dépit de sa capacité de résistance, d'affirmation de personnalité face à la colonisation culturelle, il était grave que ces valeurs spécifiques fussent à jamais perdues, face à l'urgence de l'économique et du social qui mobilisait les hommes et les capitaux pour les tâches productives. Les puissances occidentales restaient elles-mêmes peu réceptives aux problèmes des arts nègres, leur intervention se limitant aux achats d'œuvres d'art.

Qu'il définisse le socialisme africain (Senghor 1971:252-257 ; Diagne 2007:138-144), qu'il étudie les plans de développement économique, qu'il se penche sur l'éducation et la formation, qu'il élabore la doctrine du partiÉtat de l'époque, l'Union Progressiste Sénégalaise, Senghor ne manquait jamais de mettre l'accent sur la nécessité d'un humanisme total qui nourrit et développe à la fois le corps et l'âme (Senghor 1964:70-82 ; 133-146 ; 202-217). ${ }^{1}$ Il soulignait que la priorité de l'économie ne s'opposait pas à la primauté de la culture. Il était dans l'essence même de la politique du Sénégal de défendre les valeurs de la civilisation nègre, d'être le fer de lance des jeunes États africains sur le plan de l'éducation, de la culture et de la formation. Aussi consacrait-il 33 pour cent du budget national à ces secteurs. La politique interventionniste de Senghor dans les autres secteurs (agriculture et industrie principalement) eut peu de résultats mais l'accent mis sur la culture renforça le crédit international du Père de la Nation jusqu'à amoindrir la portée de ses échecs. Toujours est-il qu'au plan national, la culture ne se «mangeait » pas! L’Université de Dakar, par son ancienneté, son organisation, son corps professoral et ses travaux, était également le lieu d'élection pour l'intelligentsia africaine et mondiale (Senghor 1964:294-297). Par sa position géographique, Dakar semblait tendre vers les deux Amériques et les Antilles. 
Partant de ce constat, Senghor se lança dans un vaste programme d'équipement culturel et de manifestations mondiales, permettant la confrontation, la diffusion et la synthèse des arts nègres du monde entier. Les piliers porteurs de cet édifice culturel étaient l'organisation d'un Festival mondial des arts nègres et négro-africains, ${ }^{2}$ l'édification de la Cité des arts et le développement des musées et bibliothèques. Le Sénégal se lançait dans l'opération culture africaine dans un contexte politique, économique et social peu favorable et fait de tensions, ${ }^{3}$ espérant que cet effort pour la sauvegarde des cultures négro-africaines ne resterait pas sans écho et entraînerait l'adhésion des peuples. ${ }^{4}$

L’École des arts du Sénégal, héritière de la Maison des arts, créée en 1959, était constituée de deux sections, Recherches en arts plastiques nègres et Arts plastiques. Dirigée par Pape Ibra Tall et Pierre Lods (fondateur de l'École de peinture de Poto-Poto, à Brazzaville en 1951), la section Recherches proposait un « art nouveau » pour une « nation nouvelle », une authenticité africaine indépendante des conventions de l'art occidental ${ }^{5}$ (Bidima 1997:69 ; Harney 2004:7). Elle insistait sur une créativité innée de l'artiste africain et à la valeur de sa contribution originale à la civilisation de l'universel. Quant aux Arts plastiques, sous la direction d'Iba Gustave Ndiaye (1928-2008), elle offrait une formation artistique occidentale classique. L'Institut national des arts, créé en 1972, issu de l’École des arts, était un établissement d'enseignement artistique polytechnique et un organisme de recherche sur la musique, la danse, les arts dramatiques et les arts plastiques. Il avait une triple vocation, (i) rechercher, conserver et moderniser les arts africains ; (ii) enseigner les techniques artistiques universelles en les appliquant aux sources traditionnelles de l'inspiration nègre ; (iii) permettre les confrontations et les rencontres des artistes noirs de l'Afrique et du monde.

À l'origine, il devait prendre le nom de Cité des arts, bâtie sur le site de Soumbedioune, face à l'océan, dans la baie abritant les pêcheurs lebu, fondateurs de Dakar, attachés à leurs traditions. Tranquillité, beauté et sérénité seraient les compagnons des artistes en résidence et des élèves. ${ }^{6}$ Le Nouveau Théâtre, ${ }^{7}$ le Nouveau Musée (dit dynamique), ${ }^{8}$ spécialement conçu pour les expositions temporaires et le Stade de l'Amitié constituaient l'armature d'accueil des manifestations en direction du Festival. ${ }^{9}$ L'organisation de cet évènement nécessita plusieurs années de préparation (1963-1966) ; $;^{10} \mathrm{il}$ se déroula du $1^{\text {er }}$ au 24 avril 1966, avec la participation d'une quarantaine de pays d'Afrique (dont le Maroc et l'Egypte), d'Europe (France, RoyaumeUni) et de la diaspora atlantique (Etats-Unis, Brésil, Haïti, Jamaïque, TrinidadTobago, Antilles françaises), malgré les urgences économiques et sociales du Sénégal (Ficquet 2008:20-21 ; Badji 2009:14-25). Senghor en avait fait une source d'inspiration pour l'Afrique indépendante qui avait pris conscience 
de sa valeur et de son unité, et pour le reste du monde, où le continent se présentait sous son visage de producteur de civilisation, marquant l'avènement d'une ère nouvelle, celle de l'indépendance culturelle. Le but principal assigné à ce Festival était de permettre aux artistes africains de se faire connaître et se de faire entendre dans un climat d'épanouissement intellectuel. ${ }^{11}$

Les principales manifestations tournaient autour du colloque sur l'Art nègre, subventionné par l'Unesco (30 mars au 7 avril, au Palais de l'Assemblée nationale du Sénégal) (Badji 2009:26-43 ; Ficquet-Gallimard et 2009:143-150), ${ }^{12}$ des expositions..$^{13}$ et des spectacles sur scène..$^{14}$ Au titre des grands prix littéraires, Cheikh Anta Diop se vit attribuer le Prix spécial du jury comme l'auteur noir qui a le plus influencé la pensée du XXe siècle avec Nations nègres et culture. Ibou Diouf reçut le prix de dessin de tapisserie ; Ousmane Sembene fut lauréat du Festival en cinéma (La Noire de...) et en roman (Vehi Cossan). Aimé Césaire a dit de lui : « Docker, devenu romancier et écrivain, Sembene Ousmane symbolise l'accomplissement de l'homme africain qui, grâce à un effort personnel et constant, a réussi à s'imposer à l'attention du monde par la valeur certaine de sa création artistique, la variété de la peinture qu'il a donnée des milieux populaires et la probité de sa vision africaine ». Le Festival de Dakar eut la particularité de mettre en public la théorie senghorienne de l'enracinement et de l'ouverture (civilisation de l'universel) (Senghor 1977) et sa vision de faire de Dakar un pôle essentiel du panafricanisme culturel et de l'intégration africaine. ${ }^{15}$

À côté d'une esthétique du rythme et des parallèlismes asymétriques qui imprimait une direction précise à l'École des arts du Sénégal dans laquelle triomphaient les théories et idées de Senghor, le «mécénat d'État » (Sylla 1998:1; Snipe 1998:53-54) est une autre particularité de l'action culturelle au cours des vingt premières années d'indépendance. L'École de Dakar canonisait l'esthétique de l'africanité dans les arts plastiques (peinture, sculpture, architecture, arts graphiques et communication, environnement et tapisserie) et était fortement influencée par Senghor qui orientait les bases de la création par des interventions directes auprès des artistes régulièrement convoqués au Palais. Le genre d'art moderne produit par la section Recherches répondait à l'appel de Senghor pour qu'un art national représentât la nation nouvellement indépendante. Sous Senghor, la culture était mise au service de la diplomatie. L'art moderne sénégalais, de par ses thèmes et styles, ${ }^{16}$ donnait une illustration des idées de la négritude. De 1960 à 1980, les artistes de l'École de Dakar (Pape Ibra Tall, André Seck, chef de la division sculpture et céramique, Ibou Diouf, lauréat du Festival, Bocar Pathé Diongue, Chérif Thiam, Abdoulaye Ndiaye Thiossane, Diatta Seck, Philippe Sène, Oumar Katta Diallo, Modou Niang, Amadou Seck, Ousmane Faye, Amadou Ba) (Diouf 1999:89-152 ; Harney 2004:49-104) ont dominé la vie et la scène 
artistiques au Sénégal et à l'étranger, notamment à l'occasion des expositions itinérantes ; leurs œuvres étaient régulièrement achetées par l'État et tissées prioritairement par la Manufacture de tapisserie (Sylla 1998:67, 123).

Pour faire apprécier les valeurs profondes de la négritude, Senghor montrait ses artistes à l'occasion du Salon des artistes sénégalais ou Salon de Dakar, au Musée dynamique (1973, 1974, 1975 et 1977) (Pataux 1973:67-71) ou des Semaines culturelles (Tunis, Yaoundé, Brazzaville, Fort-de-France, Pointe-à-Pitre, Bucarest, Bruxelles...) et Arts sénégalais à l'étranger. ${ }^{17} \mathrm{Il}$ n'est donc pas surprenant que du temps de la toute puissance de Senghor, tous les créateurs dans les arts plastiques s'inspiraient ou tenaient compte de ses idées et théories, entraînant la marginalisation des artistes qui contestaient les thèmes et pratiques de cet art d'une « indéniable africanité » (Alpha Walid Diallo, Souleymane Keïta, Mor Faye, Mamadou Niang et Souleymane Faye). L’École de Dakar a suscité interrogations et controverses. ${ }^{18}$ Iba Gustave Ndiaye, peintre récemment disparu, assez éloigné des conceptions et vues de Senghor, prit ses distances vis-à-vis de cette École. « Je suis un africain peintre » (Ndiaye 1987:70). Au Festival de 1966, il reçut une mention spéciale pour l'ensemble de son œuvre. Son exil à Paris à partir de 1967 n'y est pas étranger. Iba Ndiaye Djadji (critique d'art décédé en 2003) qualifiait l’École de Dakar de "vaste escroquerie intellectuelle », ${ }^{19}$ reprise mimétique de l'École de Paris et perpétuation des tropes primitifs sur l'Afrique.

Les peintres de l’École de Dakar, appelés les peintres de la négritude, donnaient une faible impression de créativité et se contentaient des critiques du président-poète. Senghor avait théorisé et élaboré une Négritude et une esthétique sur la base desquelles il avait créé de nouveaux arts plastiques (peinture, sculpture, architecture, tapisserie). Mais l’École de Dakar était sans maître, même si le soubassement théorique existait. Ni Pierre Lods, ni Iba Ndiaye, ni Pape Ibra Tall ne s'en sont réclamés. À l'École des arts même, il n'y avait pas d'enseignement théorique sur la négritude, sur l'art africain ancien et très peu d'éléments sur l'histoire de l'art. ${ }^{20}$ Ainsi, en hiérarchisant la pratique culturelle, entre les «arts nobles » offerts à l'appréciation esthétique et les " arts populaires » soumis à la curiosité « ethnologique » (qui, selon lui, n'élevaient pas l'âme), Senghor développait un jugement de valeur qui ne facilitait plus la rencontre entre l'art et le citoyen et de facto créait de l'inégalité dans l'accès à la culture. Ont tiré profit de ce volontarisme d'Etat, les publics cultivés, ayant hérité d'un « capital culturel » suffisant pour une confrontation directe avec les œuvres. Face à un projet étatique qui ne démocratisait pas la culture, naquit à la fin des années 1970, un groupe d'opposants constitué d'artistes, d'écrivains, de comédiens, appelé les Avant-gardistes (Snipe 1998:87-89 ; Harney 2004:105). 


\section{...à l'épreuve des réalités sous Abdou Diouf et Abdoulaye Wade}

Au début des années 1980, la générosité et le volontarisme culturels se heurtent à la réalité économique. La situation économique et financière du Sénégal est changeante : la crise économique grave, les programmes d’ajustement structurel, les réorientations et les nouvelles priorités (lutte contre le chômage et le désespoir des jeunes, contre la détérioration des revenus paysans, contre la contestation accentuée de l'autorité du pouvoir central, reprise des politiques sectorielles, notamment dans l'éducation et la santé de base) (DiopDiouf 1990 ; Diop 1992 :187-203 ; Gellar 1997 ; Touré, 1985) entraînent l'émergence, dans le domaine des arts et de la culture, de nouvelles initiatives, individuelles et collectives, privées et corporatistes qui se présentent comme alternatives au mécénat d'État. L'autonomie des artistes sénégalais se révèle plus grande tandis que le rôle de l'État dans la définition et la conduite d'une politique de la culture régresse. ${ }^{21}$

La culture et la réactivation du passé pour les besoins du présent, comme outil de consolidation du pouvoir ou forme de propagande politique, ne rencontrent plus d'adhésion. Face à cette nouvelle donne, Abdou Diouf, le successeur de Senghor à la tête de l'État, accompagne les initiatives qui se développent plutôt que d'orienter les choses depuis le sommet de l'État. Un exemple de ce nouvel état d'esprit est d'une part l'élaboration de la Charte culturelle (1982-1988) qui mobilise intellectuels, hommes et femmes de culture sans considération de leurs appartenances politiques, autour d'un processus de construction consensuel, ${ }^{22}$ et d'autre part le soutien au Festival panafricain des arts et cultures (Fespac) $)^{23}$ et la première édition de la Biennale des arts plastiques de Dakar (Dak'Art) en décembre 1992, à l'heure de la globalisation qui fait de la capitale du Sénégal un lieu de débats sur l'identité et l'art contemporains et la place des artistes africains à l'intérieur de ce contexte global.

Dak’Art, devenue Biennale de l'Art Contemporain, reste un exemple réussi de créer et de faire vivre des rencontres culturelles en Afrique où se côtoient des produits dans un esprit de concurrence esthétique. Instituée depuis 1989, sur initiative de l'Etat du Sénégal, la première édition était dédiée aux Lettres en 1990. La Biennale a été reconfigurée à partir de 1992 pour être réservée à l'art contemporain africain. Après une dizaine d'années de léthargie des artistes de l'Ecole de Dakar, la Biennale de 1992 a consacré cette Ecole, sur initiative d’Abdou Diouf. Ces pionniers de l'art au Sénégal (Ibou Diouf, Diatta Seck, Chérif Thiam, Amadou Seck, Maodo Niang) ont également participé aux deuxième (1996) et troisième (1998) éditions. La diaspora fait son entrée en 1998 et à partir de 2000, l’initiative privée s’implique davantage en organisant une série de manifestations individuelles ou collectives qui prend le nom de 
Dak'Art Off (51 expositions en 2000 à 200 en 2010, à Dakar et à l'intérieur du pays (Saint-Louis, Thies, Ziguinchor...).

Depuis 2000, une certaine morosité touche les circuits de diffusion de la culture, marquée par l'absence d'un véritable management. ${ }^{24}$ L'inexistence d'une réelle politique muséographique et de galeries d'art cohérentes affaiblit les réponses attendues par les artistes. La précarité des espaces de création et le manque de cohérence des modes d'organisation et des manières de procéder pour l'épanouissement du patrimoine culturel rendent difficile le cheminement durable des vocations artistiques. Toutefois, des actions vigoureuses ont été menées dans la numérisation des Archives culturelles (dont le service a été créé en 1967), dans l'inventaire, la collecte et le classement du patrimoine matériel (quelques 400 sites et monuments ont été recensés entre 2003 et 2007 sur le territoire national dont 137 pour la région de Dakar. L'arrêté du ministère de la Culture et de la francophonie, daté du 12 septembre 2007 portant publication de la liste des sites et monuments historiques classés, donnait corps à la loi du 25 janvier 1971 fixant le régime des monuments historiques et celui des fouilles et découvertes) et immatériel.

Les grands projets culturels d'Abdoulaye Wade (Musée des civilisations noires, Place du souvenir africain, Monument de la renaissance africaine, Grand théâtre, Ecole des beaux-arts, Bibliothèque nationale et Maison des archives, Musée des arts contemporains, Place de la musique, troisième édition du Festival mondial des arts nègres) suscitent controverses et débats. Ont été réalisés à ce jour la Place du souvenir africain, le Monument, le Grand Théâtre et le Troisième Festival mondial des arts nègres. Le Mémorial de Gorée, projet sous le mandat présidentiel d'Abdou Diouf, ne semble plus au goût du jour. Enfin la marchandisation de la culture (rapprocher les secteurs de la culture et de l'économie) et le cosmopolitisme ont profondément investi et modifié le champ. Le secteur culturel représente un énorme marché qui a tendance à creuser les échanges inégaux, avec la logique de concentration des industries culturelles qui conduit à un repli des cultures minoritaires, à une peur de l'uniformisation (l'américanisation) qui alimente les débats.

\section{Culture alternative et espace public}

Au-delà des aléas liés à la politique culturelle étatique, une question importante qui traverse le monde de la culture et des arts de 1960 au début du troisième millénaire tourne autour de l'acte de création et de son audience. Sous Senghor, le public gravite autour de Dakar et des élites. Or ce qui caractérise nombre d'artistes sous Senghor et Abdou Diouf, ce n'était pas seulement sortir du formel mais créer à partir du quotidien, de l'anti-héros, du désespoir 
sarcastique et rigolard, sans souci du démonstratif, briser l'opposition entre savoir « expert » et savoir « populaire ", s'élever contre une conception massive et fixiste de l’identité, échapper au mécénat et au clientélisme, en somme aller à contre-courant de ce trop-plein d'identité pour faire émerger des publics alternatifs et mieux rendre compte des transformations multiples intervenues dans la culture et l'imaginaire politiques. Au Sénégal, la culture et les arts ne peuvent pas se lire uniquement sous la contrainte des années d'ajustement qui renvoient à l'esprit de débrouille et aux stratégies de survie mais également à cette possibilité de les rendre visibles mais en dehors de la " chose publique », c'est-à-dire en dehors de tout ce qui relève des ressources publiques et qui est géré par l'État au nom de la population. La culture ne pouvait plus continuer à être cooptée à des fins politiques; les rapports entre les artistes, l’État et le public étaient reconfigurés. Ce constat, déjà balbutiant sous Senghor, devient pérenne au début des années 1980.

Un avantage de conceptualiser des sites de la culture populaire en tant que publics, c'est qu'il évite la connotation élitiste de Habermas de son concept de l'espace public (Habermas 1989:14-26). Souvent, la culture populaire engage, interagit et répond à des débats officiels. Le concept est souvent défini en termes d'oppositionalité au pouvoir, comme il ressort de la définition de Stuart Hall, « La culture populaire, particulièrement, s'articule autour de cette contradiction : les forces populaires s'opposant à la sphère du pouvoir » (Hall 1982:238). Hall tire sa définition d'Antonio Gramsci, qui considère la culture populaire comme l'arène où l'hégémonie est contestée.

À cet égard, la culture populaire peut être considérée comme un espace public où les Africains ordinaires sont capables de débattre de questions, de soulever des sujets de préoccupation et d'agir (Dolby 2006:42). Karin Barber a soutenu que le plus important attribut de la culture populaire en Afrique est son pouvoir de communiquer, car « pour la majorité des Africains, les arts sont la seule voie de communication publique mise à leur disposition » Barber 1987:2). Et comme elle le fait remarquer, cela est particulièrement vrai dans un climat où l'élite au pouvoir domine l'espace public :

En Afrique, les gens ordinaires ont tendance à être invisibles et inaudibles. Dans la plupart des États africains, des élites numériquement minuscules s'emparent non seulement d'une part largement disproportionnée de la richesse nationale, mais elles prennent également toute la lumière. Les journaux, la radio et la télévision offrent une image magnifiée de la classe qui les contrôle. Non seulement l'élite au pouvoir fait la une, l'actualité comme en témoignent les rapports exhaustifs infinis des discours des politiciens, les comptes-rendus des mariages d'élite et des fêtes d'anniversaire et les pages nécrologiques onéreuses (Barber 1987:3, traduction de l'auteur). 
D'où l'importance des chansons, des blagues et du théâtre comme voies importantes de communication pour les personnes qui ne sont pas autorisées à accéder aux médias officiels. Barber considère la culture populaire comme un espace dominé par « un sentiment envahissant de nous et eux, même si les frontières entre ces catégories peuvent être très perméables et changeantes » (Barber 1997:4). Toutefois, cela ne veut pas dire que la culture populaire est nécessairement fondée sur la classe. Elle n’est pas en soi liée à une couche particulière de la société. Barber estime le terme 'populaire' plus comme un champ d'exploration qu'une identité stable. La culture populaire est définie dans son opposition à eux, souvent les élites politiques.

\section{Ousmane Sembene et le cinéma politique}

Dans un registre qui traverse les générations, la trajectoire d'Ousmane Sembène (1923-2007) rend compte de cette réalité culturelle faite de résistance. D’abord écrivain (parmi son œuvre, citons Oh Pays, mon Beau peuple, 1957, Les Bouts de Bois de Dieu, 1960, Voltaïque, 1962, L'Harmattan, 1964, Le Mandat, 1965, Xala, 1974), Sembene s'est rendu compte que l'écriture créait autour de lui une audience étroite (Shaka 2003:376). Son saut dans une forme d'art populaire, précisément le cinéma, lui permettait de rendre compte d'une réalité postcoloniale massive, héritière du legs colonial en termes d'atrocités, d'exploitation, de corruption, à changer par les populations (Mandabi 1968, Xala 1974, Ceddo 1977, Camp de Thiaroye 1988, Guelwaar 1992, Moolaade 2005). Le cinéma se révélait comme un donner à voir, un donner à comprendre. Tout cela explique ses déboires avec le régime senghorien (notamment sur la question de l'orthographie de Ceddo) qui rendaient plutôt compte de l'influence de ses films sur la population, de sa critique des élites africaines issues de la modernité coloniale, de la dénonciation de la politique française (de Giscard d'Estaing et de Mitterrand) en Afrique, de sa volonté de prise de distance du patronage et des différences d'approche en matière de production cinématographique. Sembène le souligne : «...Europeans often have a conception of Africa that is not ours " (Diawara 1992:32). Réou Takh (la ville, fiction, 1972) de Mahama Johnson Traoré (1942-2010) avait également fait l'objet de censure.

Au Festival d’Alger de 1969, Momar Thiam (né en 1929) et Djibril Diop Mambéty (1945-1998) avaient respectivement présenté La Malle de Maka Kouli (d'après le conte de Birago Diop) et Contras' City (La Ville de contrastes). Le cinéma alternatif néoréaliste (importance du décor naturel et de l'extérieur) avec Mahama Johnson Traoré, Djibril Diop Mambéty, Momar Thiam et Tidiane Aw (1935-2009) et Ben Diogoye Beye (1947), développait sa propre trajectoire dans les cinéclubs (lycées, quartiers populaires) et au 
Centre culturel français de Dakar. Se consacrant exclusivement au genre documentaire, Samba Félix Ndiaye (1945-2009) sort Perantal (1975). Mister Doc (pour reprendre la belle formule de Baba Diop) est considéré comme le père du film documentaire sénégalais. ${ }^{25}$ Pour sortir du contexte sénégalais, le Malien Souleymane Cissé avec Finye (film politique qui décrit la corruption et la stérilité des régimes militaires en Afrique, 1982) rencontrait les mêmes difficultés pour produire son film. Considéré comme très critique à l'instar d'Ousmane Sembène, la Coopération française suspendit son assistance financière et technique en 1980 jusqu'à l'arrivée du gouvernement socialiste de Mitterrand qui reprit l'aide et permit l'achèvement du long métrage. ${ }^{26}$

Le Front culturel sénégalais : éveiller les consciences et bâtir une société nouvelle

Au début des années 1970, dans la clandestinité, des forces politiques et culturelles (musiciens, poètes, hommes de théâtre, cinéastes...), résolument opposées aux orientations politiques et à l'aliénation culturelle senghoriennes s'organisent au sein d'un mouvement alternatif, le Front culturel. ${ }^{27}$ Déjà lors du Festival mondial des arts nègres, les mouvements de libération de l'Afrique portugaise (Parti Africain pour l'Indépendance de la Guinée et du Cap-Vert, Front de Libération du Mozambique...), Cuba, la Guinée de Sékou Touré, l’Algérie de Houari Boumediene, partisans d'un anticolonialisme ou d'un antigaullisme radical, avaient montré la voie et n'étaient pas représentés. Quant à l'Organisation de l’Unité Africaine (OUA), créée en 1963, elle avait observé une position de neutralité. Trois ans plus tard, en 1969, Alger accueillit une manifestation de même ampleur, organisée sous l'égide de l'OUA, le Festival culturel panafricain qui, prenant le contrepied de la philosophie de Senghor, œuvrait pour la liaison arts-action politique et vit la participation des fronts de libération des pays sous domination portugaise, l'African National Congress sud-africain, la Zimbabwe African People's Union, les Black Panthers américains et l'Organisation de Libération de la Palestine. Le Front luttait pour une culture nouvelle, anti-impérialiste et anti-féodale qui supplanterait une culture rétrograde de soumission et d'asservissement à la France, représentée par la figure de Senghor. ${ }^{28}$ Le Front s'assignait comme objectif de sensibiliser le peuple sur la réalité qu'il vivait et de contribuer à l'affirmation d'une culture populaire authentique. Comme Senghor, le combat culturel servait le combat politique au sein du Front, en vue d'instaurer une société nouvelle pour un homme nouveau. «Le Front culturel était l'instrument par lequel communiquer avec les populations et seuls les artistes, à l'instar de Senghor, pouvaient le faire $» .{ }^{29}$

Très tôt, le Front culturel avait identifié le choix senghorien de la primauté d'une culture élitiste. ${ }^{30}$ La lutte de libération nationale allait de pair avec un 
processus constant de luttes idéologiques où le mouvement culturel progressiste $^{31}$ élevait la voix contre l'exploitation et l'oppression et posait le lien dialectique entre processus de libération nationale et développement des langues nationales. S’inspirant de modèles inconciliables, la confrontation était inévitable. Le Front s’était engagé dans une critique acerbe de la politique culturelle de Senghor et se nourrissait de diverses traditions. ${ }^{32}$ Aux yeux de ses membres, Senghor symbolisait la figure d'une Négritude réactionnaire et mystificatrice, de l'individualisme de la société capitaliste occidentale, nourri de la culture et de l'ethnologie bourgeoises impérialistes et « vêtu d'un boubou aux senteurs folkloriques $» .{ }^{33}$

Le Front s’attaquait également au pouvoir des confréries religieuses, principal soutien de Senghor, qualifiées de féodalités réactionnaires interprétant faussement les textes sacrés de l’islam pour river la paysannerie analphabète et laborieuse dans des rapports patriarcaux et la résignation. ${ }^{34}$ La tâche du Front ne fut pas aisée pour contrebalancer la force brute $d u$ monopole d'État (Hall 2009:374). Les émissions de radio (Kër noflaay, Tann sa bula neex) et de télévision (Diamonoy tey, Caaxaan faaxe), en raison de leur diffusion en langue nationale, le wolof, rencontraient un grand écho auprès des populations, en dépit de la critique faite par le Front de leur contenu féodal. ${ }^{35}$ D’où l'accent mis par le Front, dans sa stratégie, sur l'école des masses, sorte de formation à l'éveil de conscience des masses populaires sous les formes écrite, gravée, sculptée, chantée (Leebi Goolo), dessinée, mimée. L’effort portait non seulement sur la production en langues nationales mais également en français, pour la diffusion à l'étranger des œuvres littéraires et artistiques, exprimant les aspirations et les pensées populaires. ${ }^{36}$

Comment toute cette production populaire alternative a-t-elle pu se décliner dans l'espace urbain ? Elle fut frappée d'interdiction et se développa dans la clandestinité. Par le biais du théâtre et de la musique, elle était très présente dans les milieux scolaire et estudiantin, associatif (associations sportives et culturelles), la presse (Kàddu animé entre autres par le linguiste Pathé Diagne, Waraango). Sans nier l’importance du travail culturel, le bilan est cependant mitigé, notamment en terme de changement de la société. Plus qu'un front, ce mouvement s'était plutôt singularisé par son sectarisme : il était l'expression du courant maoïste. ${ }^{37}$ De plus ses difficultés (défaut d'une réflexion locale suffisante sur la nature de l'État et les stratifications sociales), son reflux (lié à la réflexion étatique) ont accéléré la crise du mouvement politique de gauche traversé lui-même par des conflits. ${ }^{38}$ Se basant sur le marxisme et les différentes variantes du nationalisme, le Front qui cherchait à construire une identité porteuse de décolonisation culturelle 
occupait une position subalterne par rapport aux dirigeants du parti-État et des partis clandestins. ${ }^{39}$

\section{Des Avant-gardistes aux artistes des années 2000 : entre précarité, autonomie et marché}

Également au sein même des artistes ayant bénéficié du soutien de Senghor, la fronde s'organisa au début des années 1970. Plusieurs d'entre eux formés à l'Institut national des arts du Sénégal commencèrent à se rencontrer au Café Terrasse, jouxtant le Théâtre national Daniel Sorano et à conceptualiser leurs pratiques dans des voies novatrices, cherchant à s'émanciper du monopole de l'État (unitarisme senghorien) et à « débloquer » l'artiste en termes d'expression, de pratique et d'interprétation. Leur souci était d'aller au-delà des caractéristiques stylistiques et idéologiques de leurs mentors. L'art devenait un lieu de lutte et de jeu de pouvoir ; devenu politique, il mobilisait des artistes qui discutaient et agissaient à l'intérieur d'espaces où ils laissaient libre cours à leur imagination dans une temporalité locale et globale (Diouf 2002:282 ; Diouf 2003:6) qui reconfigure les rapports complexes entre l'artiste, l'État et le public. À travers des associations et des ateliers qui constituaient des fora de voies alternatives, ils intégraient également l'art dans les préoccupations internationales, dans le cosmopolitisme mondial. De ces discussions sont nés à la fin des années 1970 le Laboratoire Agit Art installé au Village des Arts de 1977 à 1983 (à l'intérieur du Camp militaire désaffecté Lat Dior) et regroupant quelques 80 artistes et dont les figures de proue sont Issa Samb dit Joe Ouakam (sculpteur, peintre, écrivain et critique) et El Hadj Moussa Babacar Sy dit El Sy (peintre) et la Cité des Artistes Plasticiens (tous peintres) de Colobane. Ils se considèrent comme membres des seconde et troisième générations. ${ }^{40}$

Leurs méthodes de travail communautaires utilisaient beaucoup les matériaux locaux de récupération. La rupture de ces artistes, influencés par les critiques de la Négritude tels Stanislas Adotevi, Wole Soyinka, Sembène Ousmane, avec le répertoire stylistique et thématique de leurs prédécesseurs (Ibou Diouf, Bocar Pathé Diongue, Maodo Niang, Oumar Katta Diallo Diatta Seck, Amadou Seck...), permit de rendre compte des réalités sociopolitiques et culturelles de leur temps et de procéder ainsi à une réévaluation de la vision essentialiste de la Négritude, des notions reçues d'authenticité et d'origine et du sens de l'Africanité de l'École de Dakar (Africanness) (Harney 2004:14). Se proclamant Avant-gardistes, ils engageaient une conversation multidirectionnelle sur les techniques et esthétiques visuelles européennes. Beaucoup d'entre eux s'engagèrent également dans un travail qui ne rencontrait pas le parrainage de Senghor, notamment la peinture sous verre (Gora Mbengue). Ces avant-gardistes furent à l'origine de l'éclosion de galeries 
privées (Tenq d'El Sy, Colobane) et d'opportunités internationales, source de parrainage alternatif et de réseaux transnationaux pour les exhibitions (Whitechapel Gallery à Londres pour Agit'Art en septembre 1995), même si, il faut le souligner, ce furent souvent des expériences individuelles. ${ }^{41}$

La génération d'artistes des années 1990 et 2000 utilise une variété d'approches, de discours et de supports. Parmi ces créateurs, citons les plasticiens (Kalidou Kassé, Amadou Kan-Si, Mor Faye, Seynabou Sakho, Félicité Codjo), les graffiteurs qui déclinent un langage visuel sur les murs de Dakar (Soly Cissé, Modou Dieng, Iba Sow), les photographes (Ousmane Ndiaye Dago, Fatou Kandé Senghor, Pape Samba Seydi, Jacques Daniel Ly, Betty Weber), les vidéastes (Abdoulaye Kane Minar, Isabelle Blanche, Arfang Sarr-Crao) et ceux qui poursuivent le travail dans la récupération, avec des compositions aux techniques mixtes à partir du fer (Ndary Lo, Issa Diop, Dame Coundoul), du bois (Abdou Wahab Gueye, Seydina Sané), du verre. Cette génération qui exerce ses activités à Dakar, sa banlieue (Association des artistes plasticiens de Pikine, Fondation Metropoli à Guediawaye) ou à l'intérieur du pays développe une réflexion critique sur sa propre production et reste consciente du rôle des galeries et des critiques dans la diffusion de l'information relative aux artistes et à leurs œuvres. Le dialogue transnational se fait par les expositions internationales, les workshops, les résidences et le Net. À la différence des années 1960 et 1970, pendant lesquelles l'ouverture au plan international était limitée aux expositions sponsorisées par le gouvernement sénégalais, ces artistes sont entrés sur la scène de l'art local et international à travers diverses expositions en solo.

L'analyse de la culture alternative reste à affiner pour en saisir les nuances, pour « la redécouverte du sujet subalterne et le stress de sa créativité », qui a « pris la forme d'une interminable invocation des notions 'd'hégémonie', 'd'économie morale', 'd'accommodation' et de 'résistance' » (Mbembe 2001:5). Les dirigeants cherchent à revendiquer des espaces publics par le biais de leurs cérémonies d’État dispendieuses qui affichent la grandeur de leur puissance, mais en même temps, les administrés parviennent à se tailler un espace pour eux-mêmes, constituant donc leurs propres publics populaires alternatifs à côté des publics officiels.

\section{Conclusion}

L'espace public au Sénégal a été le lieu de contestation culturelle où se sont constituées diverses identités à travers leur expérience des formes de médiation dans les pratiques de la vie quotidienne. La notion de culture populaire alternative peut être utile pour comprendre comment ce processus de contestation évolue, par des gens qui discutent et agissent, pour faire face à l'adversité de Senghor considéré, à leurs yeux, comme l'opposant 
acharné des revendications populaires légitimes de leur époque. La mise en public de la culture fortement marquée par l'ombre de Senghor a été un site de lutte et de négociation d'identités multiples. Elle a été une arène de consentement et de résistance. L'héritage de Senghor ouvre également le débat sur le rôle de l'artiste et les rapports entre identité et pratique artistique dans un univers globalisé. Une double interrogation qui ne manque pas d'être posée en ce XXIe siècle tourne d'une part, autour de l'appropriation et de l'actualisation de la fonction expressive de l'art par le Sénégalais pour lui donner son sens culturel et d'autre part, la pertinence d'un art nègre qui traverse la politique et les pratiques culturelles de 1960 à nos jours.

Le projet senghorien de rassembler les Sénégalais autour de valeurs communes, de fonder un sentiment d'appartenance à partir de l'art et de la culture, d'assurer la cohésion nationale a réussi même si les transformations économiques et sociales n'ont pas suivi. Si on peut lui reprocher un projet culturel trop élitiste, il est à noter que ses successeurs (Abdou Diouf et Abdoulaye Wade) n'ont pas véritablement réussi l'intégration de l'art dans l'agenda social. Faut-il des actions pédagogiques ou de médiations pour une appropriation savante/populaire des œuvres ? Est-il nécessaire au(x) public(s) d'avoir une connaissance préalable de l'art ? Toujours est-il qu'il est utopique de prêter à la politique culturelle la tâche de contrer les effets de la stratification sociale alors même que l'école n’y est pas parvenue. Au Sénégal, l'éducation artistique n'a pas une couverture nationale; il n'existe pas un corps d'inspecteurs d'éducation artistique. De plus, l'évasion culturelle à peu de frais, à l'image des telenovelas hispanophones ou lusophones (histoires d'amour, problèmes d'escroquerie...), feuilletons quotidiens de soirée, douze mois sur douze, augmente à brouiller l'ordonnancement et l'intérêt des citoyens pour la restauration du patrimoine immatériel national.

L'expression nègre fait-elle référence à un genre artistique ou à un ensemble de pratiques artistiques propres aux Noirs ? Senghor expliquait sa volonté d'organiser le premier Festival des arts nègres dans un souci de parvenir à une meilleure compréhension internationale et interraciale, en exposant la contribution des artistes et écrivains noirs aux grands courants universels de pensée (Ficquet et Gallimardet 2009:137-139). En résumé, rendre les Noirs conscients de leurs valeurs culturelles de civilisation et les amener à engager un dialogue avec les valeurs complémentaires des autres civilisations. L'on peut se demander aujourd'hui en revenant au sens plénier du mot nègre avec sa référence à la couleur noire, s'il ne représente pas une sorte de camisole qui enfermerait l'artiste dans la prison de sa peau. L'expression ne renvoie plus à aucune référence objective qui regrouperait des pratiques artistiques propres aux Noirs. Dans deux documentaires réalisés par Laurence Attali (Dimé 1994) et Beatrice Soulé (Ousmane Sow 1996), 
les deux sculpteurs se démarquent d'un art africain. Dimé (1953-1994) s'exprime ainsi : « je n'accepterai jamais que l'Occident m'enferme dans ce concept d'art africain. Je ne cherche pas à travailler comme un Africain. Je cherche à travailler comme Moustapha Dimé parce que Moustapha Dimé, c’est moi ; c'est pas les autres ». " Ousmane Sow définit ses sculptures comme ni africaines, ni européennes ». Elles sont

En consonance, on peut évoquer L'Éloge de la créolité (Bernabé, Chamoiseau, Confiant, 1989) : « Ni Européens, ni Africains, ni Asiatiques, nous nous proclamons créoles » (cité par Diagne 2007:157). S'il est possible de concéder à Senghor l'emploi du vocable « arts nègres » car son combat était celui de la reconnaissance de l'humanité des Noirs par leur capacité à produire des œuvres de qualité, il est peut-être temps pour nos écrivains, nos poètes, nos peintres et nos musiciens de sortir de cette condition chromatique, sans pour autant renier leur histoire, leur culture, pour que leurs œuvres soient jugées à leur juste valeur. L'africanité est et doit rester une question ouverte sans cesse explorée (Diagne 2007:160). Le troisième Festival mondial des arts nègres, sous le mandat présidentiel d'Abdoulaye Wade ${ }^{42}$ est placé sous le thème de la Renaissance africaine. ${ }^{43}$

\section{Notes}

1. Entretien avec Aminata Diaw, professeur de philosophie, Université Cheikh Anta Diop, Dakar, 22 mai 2008.

2. Tel est l'intitulé du Festival, prévu pour devenir une biennale, qui eut lieu à Dakar en 1966.

3. Non-remise en cause du modèle économique hérité à l’indépendance, échec relatif du $1^{\text {er }}$ plan quinquennal de développement, crise de l'arachide (principal produit d'exportation), budget de l'Etat dépendant des prêts de la France, crise au sommet du pouvoir et éviction de Mamadou Dia, président du Conseil du Gouvernement en décembre 1962, crise de l'arachide, principal produit d'exportation...

4. Entretien avec Penda Mbow, professeur d'histoire, Université Cheikh Anta Diop, conseiller au ministère de la Culture sous Senghor, ministre de la Culture sous Abdoulaye Wade, Dakar, 31 mai 2008.

5. Al’image de Pierre Lods (décédé en 1989) au Congo français et au Sénégal, des Européens jouèrent, entre les années 1940 et 1960, un rôle similaire en matière d'introduction et de développement de matériaux et méthodes artistiques : Romain Desfossés au Congo belge, Margaret Trowell en Ouganda, Ulli et Georgina Beier au Nigeria, Botbol en Côte d'Ivoire.

6. Entretien avec Assane Seck, universitaire, successivement ministre de l'Education, des Affaires étrangères et de la Culture sous Senghor. Dakar, 2 mars 2008. 
7. Achevé en 1965 et dénommé Théâtre national Daniel Sorano, du nom du comédien sénégalais disparu en 1962, cette salle de 1200 places avait pour mission de susciter des confrontations africaines et de permettre au théâtre négro-africain de se perfectionner et d'élaborer son propre style, tout en élargissant son inspiration en brisant le cercle étroit du folklore pour universaliser ses techniques spécifiques.

8. Après avoir abrité la grande exposition sur l'art traditionnel au Festival mondial des arts nègres en 1966, il servit de galerie d'exposition aux œuvres des talents de l'Ecole de Dakar et des artistes étrangers (Chagall en mars 1971, Picasso en avril 1972, Soulages en novembre 1974, Iba Ndiaye, 1977). Senghor entendait par « dynamique » toute manifestation d'art, notamment plastique, où le public guidé dans sa visite par les suggestions du choix, des rapprochements, est convié à un véritable spectacle artistique, continuellement renouvelé. Par les techniques d'éclairage et de sonorisation, une statue, un masque ; un visage ou une main surgissant d'un tableau souligne leur force et leur sens. On peut même placer des personnages, faire intervenir musiciens et danseurs. Le Musée fut ensuite affecté à Mudra Afrique, encadré par Maurice Béjart, et servit avec sa section Danse, comme un moyen d'éducation artistique et d'échanges culturels entre l'Occident, l'Orient et le monde noir. Le Musée fut fermé après le retrait de Senghor de la vie politique (1980) et mis à la disposition de la Justice en 1984 (Cour Suprême puis Cour de Cassation et enfin nouvelle Cour Suprême). Entretien avec Alphonse Raphael Ndiaye, philosophe et ethnolinguiste, ancien directeur des Archives culturelles du Sénégal. Dakar, 26 février 2008. Entretien avec Ousmane Sow Huchard, anthropologue-musicologue, conservateur du Musée dynamique et commissaire aux expositions d'art à l'étranger sous Senghor, Dakar, 12 juin 2008.

9. Une Manufacture nationale de tapisserie fut également créée en 1966 et prit plus tard le nom de Manufacture sénégalaise des arts décoratifs.

10. Des pays comme les Etats-Unis, la France, la République fédérale d'Allemagne, le Liban, l'Italie, le Maroc, le Vatican apportèrent une aide matérielle ou un concours financier important.

11. Faire connaître la contribution de la Négritude à la civilisation universelle ; permettre aux artistes noirs d'outre Atlantique d'effectuer un retour aux sources ; faire ressortir toutes les contributions de la négritude aux grands courants universels de pensée et à de nombreuses formes d'art ; apporter aux artistes africains l'occasion de rencontrer des membres de l'élite internationale dans le domaine de la littérature, de la peinture, de la musique, de la danse, du cinéma...

12. Plus précisément, «L'Art nègre : fonction et signification dans la vie du peuple et pour le peuple », Archives nationales du Sénégal (ANS), FMAN 14, Préparation du colloque sur l'art nègre par l'Unesco et la Société africaine de culture. Le Comité directeur du Colloque était composé entre autres d'Alioune Diop, directeur de la maison d'édition Présence africaine et 
rédacteur en chef de la revue du même nom, président dudit comité (Aimé Césaire, Davidson Nicol, Jacques Maquet et O. Dike vice-présidents ; R.P. Engelbert Mveng, secrétaire général) et cumulativement président du bureau exécutif de l'Association du Festival (Aimé Césaire et Fodéba Keïta, viceprésidents ; Souleymane Sidibé, secrétaire général et commissaire national du Festival). Mveng joua un rôle clé dans l'organisation du Colloque et dans l'exposition Art nègre.

13.Art traditionnel ou nègre (près de 600 objets exposés provenant d'une cinquantaine de musées ou de collections privées du monde entier) au Musée dynamique puis transféré à Paris, au Grand Palais de juin à août 1966 ; art contemporain « Tendances et confrontations » dans le Grand Hall du Palais de Justice ; artisanat vivant au Village artisanal de Soumbedioune et exposition de l'invité-vedette, le Nigeria, qualifié de Grèce de l'Afrique par Senghor, à l'Hôtel de ville. Sénégal d'aujourd'hui, n³0, avril 1966, p. 9 ; Dakar-Matin, 5 avril 1966, p. 4

14. Récitals de musique sacrée à la Cathédrale (Gospel et Negro spirituals avec Marion Williams) ; chorégraphie moderne et traditionnelle à Sorano, à la salle Daniel Brottier ; concerts au Stade de l'Amitié (Duke Ellington, Joséphine Baker) ; spectacle féérique son et lumière à Gorée, un opéra populaire à thème historique ; théâtre à Sorano (La Tragédie du Roi Christophe d'Aimé Césaire fut donnée pour la première fois en Afrique)

15.Ficquet, 2008, p. 23. Le Nigeria du Général Olusegun Obasanjo, chef d’État et maître d'œuvre, profitant de la manne pétrolière (the « triumph of oil » pour reprendre l'expression d'Apter, p. 50), organise le Festival d'arts et de culture en 1977 (Festac' 77). Voir Apter, 2005, chapitre 2, « Nigeria at Large », p. 52-83 et chapitre 3, « Producing the People », p. 87-120. Ekpo 2008, p. 26.

16. Les artistes pratiquaient une forme de réalisme qui consistait à « recopier » les images et les modèles observés. Les objets de l'art africain traditionnel étant tridimensionnels, les artistes ont tenté de figurer la troisième dimension dans leurs peintures. Le premier résultat visible est la géométrisation des formes, irrégulières, approximatives, schématiques. Cela aboutit à des analogies avec le style de l'art nègre, style dit déformant et géométrisant. Du point du vue du contenu, les thèmes chers à Senghor sont constants dans leurs œuvres. Il fallait convoquer et représenter l'Afrique ancienne et traditionnelle, l'Afrique des ancêtres et des mystères, l'Afrique pure et authentique, avec ses valeurs et ses réalités, comme les pileuses de mil, les paysages de rivière et de lagune, les joueurs de tam-tam et quantités de scènes pittoresques, souvenirs pour touristes en mal d'exotisme facile. Cet « art négrifiant », populaire et naïf, illustrait la Négritude, la créativité du Noir. Il en était de même de la sculpture, de la tapisserie et de l'architecture. Pour cette dernière, la théorie du parallélisme asymétrique, s’inspirantt du style sahélien des anciennes mosquées du Soudan occidental médiéval a été illustrée par les architectes sénégalais Pierre Goudiaby Atépa (Agence nationale de la Banque centrale des états de l'Afrique de l'Ouest et complexe Cesag à Dakar) et français 
Fernand Bonamy (Université Gaston Berger de Saint-Louis), modèles architecturaux repris plus tard dans le Zaïre de Mobutu Sese Seko, le Congo de Denis Sassou Nguesso et la Guinée-Bissau de Nino Vieira.

17.Le périple de cette exposition d'arts contemporains sénégalais débuté au Grand Palais à Paris en 1973 ne se termina qu'en 1985 après avoir séjourné dans des villes comme Stockholm, Berlin, Helsinki, Vienne, Rome, Sao Paulo, Rio de Janeiro, Mexico, Montréal, Québec, Washington, Boston, NouvelleOrléans, Atlanta, Chicago. Diouf, 1999, p. 35-38.Entretien avec Alioune Badiane, directeur de l'Ecole des arts au début des années 1980 et ancien directeur des Arts. Dakar, 20 février 2008.

18. Il est difficile de donner à l'expression «École de Dakar » une paternité (Senghor, Malraux, Pierre Lods ?).

19. Le Soleil, Dakar, 17 juillet 2001, p. 7, Seck, 2004, p. 29-46..

20. Entretien avec Abdou Sylla, chercheur à l'Institut fondamental d'Afrique noire, Université Cheikh Anta Diop de Dakar, critique d'art, Dakar, 20 février 2008 ; Sylla, 2006, p. 54.

21. Entretien avec Ousseynou Wade, conseiller culturel, Secrétaire général de la Biennale Dak’Art depuis 2000, Dakar, 27 mai 2008.

22. Entretien avec Moustapha Ka, conseiller culturel, directeur de cabinet d'Abdou Diouf, Dakar, 28 février 2008. Cette Charte nationale était un document de base, instrument opérationnel mis à la disposition de l'Exécutif, à partir de la vision des populations de la chose culturelle.

23. Le projet confié au linguiste Pathé Diagne en 1986 est finalement abandonné en 1989.

24. Le ministère de la Culture a connu depuis 2000, sous l'ère du Président Wade, successivement

25. On se reportera utilement à Imbert, 2007, p. 131, pp. 317-319.

26. Entretien avec Baba Diop, journaliste, critique de cinéma, Dakar, 12 juin 2008 Voir aussi Diawara, 1992, pp. 51-83.

27. L'émergence du Front culturel comme conséquence de la contestation universitaire et scolaire à Dakar en mars 1968 n'est pas clairement établie. Abdoulaye Bathily, à l'époque un des leaders du mouvement étudiant sénégalais, n’en fait pas cas. Voir Bathily, 1992, p. 139-161).

28. Entretiens avec Usmaan Faati Ndongo et Cheikh Gueye, membres du Front culturel, Dakar, 29 février 2008.

29. Entretiens avec Usmaan Faati Ndongo et Cheikh Gueye, membres du Front culturel, Dakar, 29 février 2008.

30. Entretien avec Abdoulaye Bathily, professeur d'histoire, Université Cheikh Anta Diop de Dakar, leader étudiant marxiste en mai 68, chef d'un parti d’opposition, Dakar, 18 juin 2008.

31. Littérature (Boubacar Boris Diop), cinéma (Sembène Ousmane, Mansour Kébé, Ben Diogoye Beye, Djibril Diop Mambéty), musique (André Birame Lo, Ouza Diallo, Seydina Insa Wade), théâtre (Momar Samb), presse (les futurs animateurs du Groupe Sud)... 
32. Mouvement chinois du 4 mai 1919, lutte anticolonialiste et antiassimilationniste (Lamine Senghor, Tovalou Quenum, Garang Kouyaté, Sukarno, Nehru, Ho Chi Minh, Frantz Fanon, David Diop), Révolution culturelle de Mao. Dès la pénétration coloniale, le combat culturel avait fait corps avec la lutte anticolonialiste et contre la politique d'assimilation.

33. Entretien avec Usmaan Faati Ndongo, Dakar, 29 février 2008.

34. Il est intéressant de souligner l'amalgame fait du christianisme comme représentant la culture de l'envahisseur. Avec du recul, ces intellectuels ne se prononcent plus sur la question, tout au moins la résument-ils en précisant qu’il s’agissait du combat à une époque précise.

35. Étudiants, enseignants, intellectuels ne parvinrent pas à faire pièce à l'influence des élites maraboutiques qui diminuèrent considérablement l'impact de leurs projets révolutionnaires et de leur thématique revendicative assis sur l'idéologie marxiste.

36. Un important travail de traduction des écrits de Marx, Engels, Lénine, Mao en langues nationales fut entrepris.

37. Entretien avec Babacar Diop Buuba, professeur de lettres et civilisations anciennes, Université Cheikh Anta Diop de Dakar, membre du Front culturel, Dakar, 27 février 2008.

38. Dès le milieu des années 1970, le mouvement communiste est affaibli par le régime de Senghor et donne naissance à plusieurs partis, Parti pour l’indépendance et le travail, Ligue Démocratique, And Jef, Organisation pour la démocratie prolétarienne, Socialistes autogestionnaires, Union pour la démocratie populaire. Voir Bathily, 1992, p. 145.

39. Entretien avec Amady Aly Dieng, économiste, libre-penseur, Dakar, 27 février 2008.

40. Ceux de la seconde génération participèrent dans les années 1970 aux salons nationaux et à quelques expositions à l'étranger. Ils poussèrent au-delà du répertoire senghorien pour trouver leur propre voie. Les membres d'Agit-Art constituent le gros de cette génération. Ceux de la troisième génération furent formés et commencèrent à exposer dans l'ère post-senghorienne.

41. El Sy, Viyé Diba, Zulu Mbaye, Germaine Anta Gaye, Kré Mbaye, Fodé Camara, Séa Diallo, Serigne Ndiaye, Moussa Tine...

42. Sur le travail de programmation (architecture traditionnelle, arts d'Afrique, arts visuels, artisanat d'art, cinéma, cultures urbaines, danse, design, littérature, mode, musique, théâtre, sciences et technologie, gastronomie, sports), on se reportera au site web du Festival mondial des arts nègres : www.blackworldfestival.com

43. L’Association « Négritude » compte organiser le Quatrième Festival mondial des arts nègres (Fesman IV) en Martinique en 2013. Ce rendez-vous, qui va coïncider avec le centenaire de la naissance d'Aimé Césaire, sera l'occasion pour le continent africain de passer le témoin à la Diaspora, avec comme invité d'honneur la communauté africaine-américaine des États-Unis ; la récente élection de Barack Obama confortant ce choix. Le Quotidien, Dakar, 
16 avril 2009, p. 6. Par ailleurs, du 5 au 20 juillet 2009, s'est tenue, sous l’égide de l'Union africaine, la deuxième édition du Festival culturel panafricain d'Alger (la première ayant été organisée en 1969). Littérature, arts visuels, cinéma, musique, chorégraphie, théâtre, patrimoine, colloques ont été mis en valeur. La capitale algérienne a accueilli des milliers d'artistes et intellectuels d'Afrique et de la diaspora. D'un budget de 60 millions d'euros, l'événement a bénéficié d'un Village d'artistes d'une capacité de 2500 lits. Quelques 1500 journalistes ont couvert les manifestations. Le Soleil, Dakar, 22 juillet 2009, p. 8.

\section{Références}

Apter, A.H., 2005, The Pan-African Nation, Oil and the Spectacle of Culture in Nigeria, Chicago and London: The University of Chicago Press.

Archives nationales du Sénégal (ANS), Dakar, Répertoire du Fonds du Festival mondial des arts nègres (1963-1967), FMAN 14, « Préparation du colloque sur l'art nègre par l'Unesco et la Société africaine de culture ».

Badji, S., 2009, « Le Premier Festival Mondial des Arts Nègres (1963-1966) », Dakar : Département d’Histoire, Université Cheikh Anta Diop, mémoire de maîtrise.

Barber, K., 1987, « Popular Arts in Africa », in African Studies Review, 30, 3, : 1-78,105-132.

Barber, K. (ed.), 1997, Readings in African Popular Culture, Oxford: James Currey.

Bathily, A., 1992, Mai 1968 à Dakar ou la révolte universitaire et la démocratie, Paris : Chaka.

Bidima, J.-G., 1997, L'art négro-africain, Paris : Presses Universitaires de France.

Diagne, S.B., 2002, « La leçon de musique. Réflexions sur une politique de la culture » in Diop, Momar-Coumba (ed.), Le Sénégal contemporain, Paris : Karthala : 243-259.

Diagne, S.B., 2007 ; Léopold Sedar Senghor. L'art africain comme philosophie. Essai. Paris: Riveneuve éditions.

Diawara, M., 1992, African Cinema. Politics and Culture, Bloomington and Indianapolis: Indiana University Press.

Diop, M.-C. et Diouf M., 1990, Le Sénégal sous Abdou Diouf. État et société, Paris : Karthala..

Diop, M.-C., 1992, Sénégal : Trajectoires d’un État, Dakar : CODESRIA.

Diouf, M., « Des cultures urbaines entre traditions et mondialisation », in Diop Momar-Coumba (ed.), 2002, Le Sénégal contemporain, Paris : Karthala : 261-288.

Diouf, M., 2003, « Engaging Postcolonial Cultures : African Youth and Public Space », African Studies Review, 46 (2) : 1-12.

Diouf, S.D., 1999, Les arts plastiques contemporains du Sénégal, Paris : Présence Africaine.

Dolby, N., 2006, « Popular Culture and Public Sphere in Africa: The Possibilities of Cultural Citizenship», African Studies Review, 49, 3, 31-47. 
Epko, D., 2008, «Festac 77 et projet de modernité africaine : des méfaits d’un nationalisme culturel excessif», Africultures, $73: 26-34$.

Ficquet, E., « L’impact durable d'une action artistique : le Festival mondial des arts nègres de Dakar », Africultures, 73 : 18-25.

Ficquet, E. et Gallimardet, L., 2009, « On ne peut longtemps nier l’art nègre. Enjeux du colloque et de l'exposition du Premier Festival mondial des arts nègres de Dakar en 1966 », in Frioux-Salgas, Sarah (ed.), « Présence Africaine ; Les conditions noires : une généalogie des discours », in Gradhiva, tome 10 : 134-155.

Gellar, S., 1997, Le climat politique et la volonté de réforme politique et économique au Sénégal, rapport préparé pour l’USAID/Sénégal, Dakar, août.

Habermas, J., 1989, The Structural Transformation on the Public Sphere: An Inquiry into a Category of Bourgeois Society, London: Polity Press,.

Hall, S., 1982, «Notes on Deconstructing the Popular», Samuel Raphael (ed.), People's History and Socialist Theory, London: Routledge and Paul Kegan: 227-239.

Hall, S., «Popular Culture and the State», in Sharna Aradhana and Gupta Akhil (eds), 2009, The Anthropology of the State. A Reader, Oxford: Blackwell Publishing : 369-380.

Harney, E., 2004, In Senghor's Shadow. Art, Politics and the Avant-Garde in Senegal, 1960-1995, Durham and London: Duke University Press: 7.

Imbert, H.F., 2007, Samba Félix Ndiaye : cinéaste, documentariste, Africain, Paris : L'Harmattan,.

Mbembe, A., 2001, On the Postcolony, Berkeley: University of California Press.

Mbengue, M.S., 1973, La politique culturelle du Sénégal, Paris : UNESCO.

Ndiaye, I.G., 1977, « A propos de l'art africain contemporain : les écoles de PotoPoto et Dakar », Balafon, 37 : 70-71.

Pataux, B., 1973 , « Le Premier Salon des artistes sénégalais, Musée dynamique , Dakar, 5 janvier - 24 février 1973 », Notes africaines, 139 : 67-71.

Seck, S., 2004, « L’Ecole de Dakar : réalité historique ou escroquerie intellectuelle ? », Ethiopiques, 70 : 29-46.

Senghor, L.S., 1964, Liberté I. Négritude et Humanisme, Paris : Seuil.

Senghor, L.S., 1971, Liberté II, Nation et voie africaine du socialisme, Paris : Seuil. Senghor, L.S., 1977, Liberté III. Négritude et Civilisation de l'Universel, Paris : Seuil.

Shaka, F.O., 2003, Modernity and African Cinema, A Study in Colonialist Discourse, Postcoloniality and Modern African Identities, Trenton-Asmara: Africa World Press.

Snipe, T.D., 1998, Arts and Politics in Senegal, 1960-1996, TrentonAsmara:Africa World Press.

Sylla, A., 1998, Arts plastiques et État au Sénégal, Dakar : Ifan Cheikh Anta Diop.

Sylla, A., 2006, L'Esthétique de Senghor et l'École de Dakar. Essai, Dakar: Éditions Feu de Brousse

Touré, M., 1985, Politique d'ajustement économique et financier, communication au Conseil national du Parti socialiste, Dakar : Maison du Parti socialiste. 
Vaillant, J.G., 2006, Vie de Léopold Sédar Senghor. Noir, Français, Africain, Paris : Karthala-Sephis.

White, B.W., 2006, « L'incroyable machine d'authenticité. L'animation politique et l'usage public de la culture dans le Zaïre de Mobutu », Anthropologie et Sociétés, 30, 2 :43-63.

Wilder, G., 2005, The French Imperial Nation-State. Negritude and Colonial Humanism between the Two World Wars, Chicago and London: The University of Chicago Press.

\section{Journaux consultés}

Dakar Matin

Le Quotidien

Le Soleil

Sénégal d'aujourd'hui 